\title{
Changes in alienation in physical education classes, school happiness, and future healthy life expectancy after the COVID- 19 pandemic in Korean adolescents
}

\author{
Seung-Man Lee ${ }^{1}$, Jung-In Yoo ${ }^{2, *,+}$ and Hyun-Su Youn ${ }^{3, *,+}$ \\ 1 Department of Physical Education, College of Education, Korea University, Seoul 02841, Korea; \\ 1sm14pe@korea.ac.kr \\ 2 Department of Physical Education, College of Education, Korea University, Seoul 02841, Korea; \\ 3 Department of Physical Education, College of Education, WonKwang University, Iksan-si 54538, Korea \\ * Correspondence: surfyji@korea.ac.kr (J.-I.Y.); younhyunsu9518@wku.ac.kr (H.-S.Y.); \\ Tel.: +82-2-3290-2310 (J.-I.Y.); +82-63-850-6623 (H.-S.Y.); \\ Fax: +82-2-3290-1345 (J.-I.Y.); +82-63-850-6666 (H.-S.Y.) \\ + The corresponding two authors (Jung-In Yoo and Hyun-Su Youn) contributed equally to this work.
}

\begin{abstract}
This study aims to investigate the changes in the structural relationship between alienation in physical education (PE) class, school happiness, and future healthy life expectancy in Korean adolescents after the COVID-19 pandemic. The data were collected from adolescents in the Republic of Korea using scales for these factors. The collected data were analyzed with frequency analysis, reliability analysis, validity analysis, independent t-test, and path analysis. The key results were as follows. First, there were partial changes in each of the parameters since the outbreak of COVID-19. Second, before the pandemic, alienation in PE class negatively affected school happiness, and school happiness positively affected future healthy life expectancy; however, alienation in PE class did not affect future healthy life expectancy showing a complete mediating effect. Third, during the pandemic, alienation in PE class negatively affected school happiness, and school happiness positively affected future healthy life expectancy; alienation in PE class negatively affected future healthy life expectancy, showing a partial mediating effect. These findings emphasize the importance and potential of school education, especially PE, in promoting happiness and healthy life in adolescents. We expect these findings to have practical implications for future research by presenting theoretical and empirical data.
\end{abstract}

Keywords: adolescents, alienation in PE class, school happiness, future healthy life expectancy, COVID-19 pandemic

\section{Introduction}

In response to the first confirmed case of coronavirus disease 2019 (COVID-19) in South Korea in January 2020, the government implemented various measures to combat the outbreak. In addition to the direct medical responses, the government proposed indirect response measures that involved the public, such as wearing a face mask and practicing social distancing (Korean Ministry of Health and Welfare, 2020 [1]). However, there have been claims that despite the benefits of the nationwide use of face masks and social distancing practices to prevent the spread of the infection, they prompt depression, anxiety, loneliness, and reduce physical activities. With the prolonged pandemic for nearly a year and six months, public health concerns have become a tangible threat. Recent studies report that the increasingly prevalent socially isolated lifestyle resulting from the pandemic adversely impacts people's health. The new regular established by lockdowns during the pandemic, including work from home, increased use of digital devices, and diminished willingness to exercise, has led to mental, physical, and social health problems [2- 
4]. Some prime examples of adverse health impacts are weight gain, poor posture, irregular sleep, stress and anxiety, and vitamin D deficiency [5-7].

Studies show that life restrictions during the COVID-19 pandemic affect adults and severely impact the health of middle school students at rapid physical growth [8-10]. Recent studies on adolescents' health during the COVID-19 pandemic document such phenomena. More specifically, they reported that COVID-19 pandemic has taken a toll on adolescents' mental health, including elevated depression, anxiety, social isolation, maladaptive behavior, and stress [11-15]. Furthermore, studies also note that adolescents have experienced a decline in their physical health. COVID-19 led to a spike in the prevalence of obesity among adolescents [16], diminished participation in physical activities [17-18], and lowered the level of physical activity involvement [19]. In addition, studies have also reported that adolescents showed a deteriorated health-related quality of life (HRQoL) [20] and poorer lifestyle habits [18, 21, 22].

However, these studies are limited because they focused solely on the physical and mental aspects of adolescents' health during the COVID-19 pandemic. Currently, there is a consensus on the notion that adolescents' health is not concretely divided into physical and mental aspects $[23,24]$. While active physical activity leads to positive mental health [25], social relationships with peers blend with these factors, thus impacting adolescents' overall health [26]. For this reason, adolescents' social health is an important topic of interest during the COVID-19 pandemic. In particular, because adolescents spend most of their day on online and offline school classes, their social health should be examined concerning their school lives or classes [27]. Thus, we aimed to explore adolescents' social health during the COVID-19 pandemic based on physical education (PE) classes, when students are most active during school, and students' peer relationships and activities are most evident [28]. In particular, we established alienation in PE class, school happiness, and future healthy life expectancy as elements of adolescents' social health to analyze the structural relationships among these parameters before and during the COVID-19 pandemic.

The first parameter, "alienation," refers to a state in which students feel distant or severed from the overall PE class atmosphere and thus develop negative perceptions and feelings [29]. Alienation in PE classes is caused by various factors, including teachers, course content, peer relationships, PE facilities, and PE uniformity [30]. In addition, repetition of boring or meaningless activities [31, 32], inappropriate interaction with the teacher [29, 33-35], competitive atmosphere [36], and poor interpersonal relationships due to low self-concept or self-esteem have also been identified as some of the major causes $[29,31,34,35,37]$.

The second parameter, "school happiness," is a cognitive and affective factor describing students' beliefs about themselves and their evaluation of their comprehensive school life based on what they experience during learning and interpersonal relationships [38]. School happiness encompasses concepts such as perceived well-being, quality of life, and life satisfaction [39].

The third parameter, "future healthy life expectancy," is the anticipated satisfaction with a healthy life in the future. In other words, it refers to one's hope or expectation that their future life would be more satisfactory [40]. This is a concept related to questions such as "Will I have a healthy life in the future?" "Will my future happy or not?" "Will my beliefs and thoughts come true?" "What type of person will I become in the future?" "How will the world be changed in the future?" For adolescents who will be future leaders, such life expectancy is more important than others. Future healthy life expectancy has been documented by many studies to be deeply associated with various factors of individuals' internal traits [41].

In this context, we cannot neglect the future life expectancies of socially healthy adolescents during the COVID-19 pandemic. Empirical studies examining the path between $\mathrm{PE}$ and school happiness to improve this are needed to prepare for the post-COVID-19 era. Such studies are significant because they help understand the complex relationships 
among various predictors of future healthy life expectancy. This is because adolescence is a period wherein individuals prepare for their independent lives as adults, and school is where they enhance their social health and cultivate their dreams. Therefore, this study investigates the structural relationships among alienation in PE, school happiness, and future healthy life expectancy among adolescents to examine the changes in their social health since the outbreak of COVID-19.

Hence, we developed the following study questions: First, are there changes in the study parameters since the outbreak of COVID-19? Second, are there changes in the structural relationships among the study parameters since the outbreak of COVID-19?

\section{Materials and Methods}

\subsection{Study Population}

In this study, we took repeated measurements from the same sample to compare the changes in the structural relationships among alienation in PE, school happiness, and future healthy life expectancy in adolescents after the outbreak of COVID-19 compared to the pre-COVID-19 period. The study population consisted of students who participated in PE in school and were purposively sampled regarding statistics studies by Yang (2006) [42], Kim, \& Cha (2006) [43], and other relevant books.

A pilot survey was conducted with PE students to evaluate the content validity of the questionnaire before the primary survey. After establishing content validity through the pilot test and expert panel discussions, the first survey round was administered to 400 middle and high school students before the COVID-19 outbreak (October 2019). Of the 400 sampled participants, 390 completed the questionnaire, and after excluding 15 questionnaires with careless responses or missing responses, 375 were included in the analysis. The second survey round conducted during the COVID-19 pandemic (August 2021) was administered to 400 middle and high school students. Of the 400 sampled participants, 360 completed the questionnaire, and after excluding 56 questionnaires with careless or missing responses, 304 were included in the analysis. The demographic characteristics of the participants are presented in Table 1.

Table 1. Participants' demographic characteristics

\begin{tabular}{|c|c|c|c|c|c|}
\hline \multirow[b]{2}{*}{ Variable } & \multirow[b]{2}{*}{ Category } & \multicolumn{2}{|c|}{ First round } & \multicolumn{2}{|c|}{ Second round } \\
\hline & & $\begin{array}{l}\text { Number } \\
\text { of cases }\end{array}$ & Percentage (\%) & $\begin{array}{l}\text { Number } \\
\text { of cases }\end{array}$ & Percentage (\%) \\
\hline \multirow{2}{*}{ Sex } & Male & 180 & 48.0 & 165 & 54.3 \\
\hline & Female & 195 & 52.0 & 139 & 45.7 \\
\hline \multirow{2}{*}{ School grade level } & Middle school & 109 & 29.1 & 172 & 56.6 \\
\hline & High school & 266 & 70.9 & 132 & 43.4 \\
\hline \multicolumn{2}{|c|}{ Total } & 375 & 100 & 304 & 100 \\
\hline
\end{tabular}

\subsection{Instruments}

We used the following instruments to test the structural relationships among alienation in PE, school happiness, and future healthy life expectancies in adolescents. The questionnaire was divided into four sections: demographics, alienation in PE, school happiness, and future healthy life expectancy. All instruments were validated in previous studies. The instruments used are described below:

\subsubsection{Alienation in PE}


Adolescents' alienation in PE was measured using the instrument developed by Kim (2005) [30] and validated by Hwang \& Lee (2014) [44], Seo, Lee, \& Song (2011) [45]. This is a 28-item scale comprising six domains (alienation in curriculum, alienation in athletic competence, alienation in peer relationships, alienation in PE facilities, and alienation in PE uniform) that uses a five-point Likert scale. The internal consistency, as measured by Cronbach's $\alpha$, was $0.816-0.923$, indicating high reliability.

\subsubsection{School happiness}

Adolescents' school happiness was measured using the instrument developed by Kim and Kim and validated by Lee (2017) [46]. This 24-item scale comprises six domains (peer relationships, relationships with teachers, self-efficacy, environmental satisfaction, pleasure in learning activities, and psychological stability) that use a five-point Likert scale. The internal consistency, as measured by Cronbach's $\alpha$, was $0.866-0.850$, indicating high reliability.

\subsubsection{Future healthy life expectancy}

Adolescents' future healthy life expectancies were measured using the instrument developed by Noh (1988) [47] and Kim \& Kim (2008) [48] after modifying the scale for use in this study. This is a 16-item scale comprising four domains (interpersonal relationship, economic life, healthy life, and self-realization) that uses a five-point Likert scale. The internal consistency, as measured by Cronbach's $\alpha$, was $0.836-0.929$, indicating high reliability.

Confirmatory factor analysis (CFA) performed to test the fit of the scales confirmed that all the fit indices were above the mark of less than 0.8 for RMR, 0.9 or higher for GFI, NFI, IFI, TLI, and CFI, and 1.0 for RMSEA: $x^{2}=381.956, \mathrm{DF}=51, \mathrm{GFI}=.909, \mathrm{CFI}=.931$, $\mathrm{NFI}=.921, \mathrm{RMR}=.052$, RMSEA=.098 (Hong, 2000).

\subsection{Data Collection}

The data were collected through an in-person questionnaire survey before the COVID-19 outbreak and an online survey after. Before the survey, we contacted the PE teacher at the study school and obtained informed consent. Then, we visited the school to explain the study's purpose and other details, and data were collected from those who consented to participate in the survey via a self-report method. The survey took less than 10 minutes to complete, and careless responses or missing values were excluded from the analysis. The second survey round conducted during the COVID-19 pandemic was administered online. Information and instructions for the study were explained in detail to obtain honest responses as far as possible. The survey took less than 10 minutes to reflect the particular context of an online survey. Consent was obtained from the school principal and students' legal guardians before the first and second rounds of surveys.

\subsection{Data Analysis}

Data collected through two rounds of the survey were analyzed using SPSS 18.0 and AMOS 18 software. First, the reliability and validity of the scales used in this study were tested using internal consistency Cronbach's $\alpha$ and CFA. Second, demographic characteristics were analyzed using frequency analysis. Third, the changes in the study parameters since the outbreak of COVID-19 compared to before were analyzed using independent $\mathrm{t}$ tests. Finally, the structural relationships among the parameters before and during the COVID-19 pandemic were analyzed using path analyses. Statistical significance was set at $\mathrm{p}<0.05$.

\section{Results}


3.1. Changes in the study parameters during the COVID-19 pandemic compared to the preCOVID-19 period

Table 2 shows the results of the independent $\mathrm{t}$-tests performed to analyze the changes in alienation in PE, school happiness, and future healthy life expectancy in Korean adolescents since the outbreak of COVID-19. Compared to before, there were partial changes in these factors during the COVID-19 pandemic. First, alienation in PE facilities was lower during the COVID-19 pandemic $(2.95 \pm 1.17)$ than pre-COVID-19 period $(3.17 \pm 1.29)$. Alienation in PE uniforms was lower during the COVID-19 pandemic $(3.23 \pm 1.14)$ than in the pre-COVID-19 period $(3.23 \pm 1.14)$. However, there were no changes in alienation in athletic competence, alienation in curriculum, and alienation in peer relationships during the COVID-19 pandemic than before. Second, the relationship with teachers' domain of school happiness was higher during the COVID-19 pandemic $(3.69 \pm 0.76)$ than preCOVID-19 period (3.52 \pm 0.93$)$. Furthermore, satisfaction with the class environment was higher during the COVID-19 pandemic $(3.35 \pm 0.89)$ than pre-COVID-19 period $(3.35 \pm$ 0.89). However, there were no changes in peer relationships, self-efficacy, and pleasure in learning activities during the COVID-19 pandemic than the pre-COVID-19 period. Finally, the economic life expectancy domain of future healthy life expectancy was higher during the COVID-19 pandemic $(3.43 \pm 0.83)$ than the pre-COVID-19 period $(3.66 \pm 0.94)$. However, there were no changes in interpersonal relationship, healthy life, and self-realization expectancies during the COVID-19 pandemic than before.

Table 2. Changes of each study parameter since the outbreak of COVID-19 (Total possible score: 5.0)

\begin{tabular}{|c|c|c|c|c|c|}
\hline & \multirow{2}{*}{ Parameter } & \multicolumn{2}{|c|}{$M \pm S D$} & \multirow{2}{*}{$\mathbf{t}$} & \multirow{2}{*}{$p$} \\
\hline & & Pre-COVID-19 & During COVID-19 & & \\
\hline \multirow{6}{*}{$\begin{array}{l}\text { Alienation } \\
\text { in PE }\end{array}$} & Alienation in athletic competence & $2.34 \pm 1.05$ & $2.35 \pm 0.86$ & -0.100 & 0.921 \\
\hline & Alienation in curriculum & $2.35 \pm 1.05$ & $2.46 \pm 0.68$ & -1.606 & 0.109 \\
\hline & Alienation in peer relationship & $1.99 \pm 0.90$ & $1.97 \pm 0.72$ & 0.215 & 0.830 \\
\hline & Alienation in PE facilities & $3.17 \pm 1.29$ & $2.95 \pm 1.17$ & 2.325 & $0.020^{*}$ \\
\hline & Alienation in PE uniform & $3.23 \pm 1.14$ & $2.78 \pm 1.03$ & 5.359 & $<0.001^{* * *}$ \\
\hline & Overall & $2.61 \pm 0.86$ & $2.50 \pm 0.67$ & 1.883 & 0.060 \\
\hline \multirow{6}{*}{$\begin{array}{c}\text { School } \\
\text { happiness }\end{array}$} & Peer relationships & $4.00 \pm 0.84$ & $4.04 \pm 0.86$ & -0.498 & 0.618 \\
\hline & Relationships with teachers & $3.52 \pm 0.93$ & $3.69 \pm 0.76$ & -2.538 & $0.011^{*}$ \\
\hline & Self-efficacy & $3.44 \pm 0.79$ & $3.38 \pm 0.72$ & 1.034 & 0.301 \\
\hline & Environmental satisfaction & $3.35 \pm 0.89$ & $3.49 \pm 0.76$ & -2.233 & $0.026^{*}$ \\
\hline & Pleasure in learning activities & $3.47 \pm 0.88$ & $3.59 \pm 0.80$ & -1.771 & 0.077 \\
\hline & Overall & $3.56 \pm 0.73$ & $3.64 \pm 0.65$ & -1.493 & 0.136 \\
\hline \multirow{5}{*}{$\begin{array}{c}\text { Future } \\
\text { healthy life } \\
\text { expectancy }\end{array}$} & Interpersonal relationship & $4.15 \pm 0.80$ & $4.09 \pm 0.73$ & 1.004 & 0.316 \\
\hline & Economic life & $3.66 \pm 0.94$ & $3.43 \pm 0.83$ & 3.274 & $0.001^{* *}$ \\
\hline & Healthy life & $3.68 \pm 0.95$ & $3.55 \pm 0.89$ & 1.916 & 0.056 \\
\hline & Self-realization & $4.04 \pm 0.87$ & $3.93 \pm 0.78$ & 1.698 & 0.090 \\
\hline & Overall & $3.88 \pm 0.79$ & $3.75 \pm 0.71$ & 2.271 & $0.023^{*}$ \\
\hline
\end{tabular}

${ }^{* * *} p<0.001,{ }^{* *} p<0.01, \stackrel{*}{*}<0.05$

3.2. Comparison of structural relationships among the study parameters between pre-and during COVID-19

Table 3 shows the results of path analyses performed to analyze the structural relationships among alienation in PE, school happiness, and future healthy life expectancies 
in Korean adolescents before the pandemic. The path model had a good fit: GFI $=0.920$, $\mathrm{CFI}=0.951, \mathrm{NFI}=0.935, \mathrm{RMR}=0.053$, RMSEA $=0.089$. Kim (2005) proposed that GFI, AGFI, NFI, TLI, and CFI of $0.8-0.9$ or higher, RMR of $0.05-0.08$ or lower, and RMSEA of 0.08 or lower indicate a good fit. Regarding our model, alienation in PE negatively affect school happiness (standardized regression coefficient $=-0.449, \mathrm{t}=-7.102$ ). Second, alienation in PE did not negative affect future healthy life expectancy (standardized regression coefficient $=-0.095, \mathrm{t}=-1.695$ ). Third, school happiness positive affect future healthy life expectancy (standardized regression coefficient $=0.530, t=8.425$ ). In other words, there was a complete mediation wherein alienation in PE affected future healthy life expectancy solely through school happiness.

Table 3. Structural relationships among the study parameters before the COVID-19 pandemic

\begin{tabular}{|c|c|c|c|c|c|c|c|c|}
\hline Hypothesis & & & ath & $\begin{array}{r}\text { Standardize } \\
\text { Regression } \\
\text { coefficient }\end{array}$ & S.E. & C.R. & $p$ & Decision \\
\hline 1 & $\begin{array}{l}\text { Alienation } \\
\text { in PE }\end{array}$ & $\rightarrow$ & $\begin{array}{c}\text { School } \\
\text { happiness }\end{array}$ & -0.449 & 0.051 & -7.102 & $<0.001^{* * *}$ & Adopted \\
\hline 2 & $\begin{array}{l}\text { Alienation } \\
\text { in PE }\end{array}$ & & $\begin{array}{c}\text { Future healthy life } \\
\text { expectancy }\end{array}$ & -0.095 & 0.058 & -1.695 & 0.090 & Rejected \\
\hline 3 & $\begin{array}{c}\text { School } \\
\text { happiness }\end{array}$ & & $\begin{array}{c}\text { Future healthy life } \\
\text { expectancy }\end{array}$ & 0.530 & 0.080 & 8.425 & $<0.001^{* * *}$ & Adopted \\
\hline$* * * x<0.001$ & \multicolumn{8}{|c|}{$\begin{array}{l}\text { Table } 4 \text { shows the results of path analyses performed to analyze the structural rela- } \\
\text { tionships among alienation in PE, school happiness, and future healthy life expectancies } \\
\text { in Korean adolescents during the pandemic. The path model had a good fit: GFI=0.886, } \\
\text { CFI }=0.923, \mathrm{NFI}=0.900, \mathrm{RMR}=0.049 \text {, RMSEA }=0.098 \text {. Regarding our model, first, alienation } \\
\text { in PE negatively affect school happiness (standardized regression coefficient }=-0.492, \mathrm{t}=- \\
5.034 \text { ). Second, alienation in PE negative affect future healthy life expectancy (standard- } \\
\text { ized regression coefficient }=-0.134, \mathrm{t}=-2.212 \text { ). Third, school happiness positively affect fu- } \\
\text { ture healthy life expectancy (standardized regression coefficient }=-0.678, \mathrm{t}=9.430 \text { ). In other } \\
\text { words, there was a partial mediation wherein alienation in PE influenced future healthy } \\
\text { life expectancy directly and indirectly through the mediation of school happiness. }\end{array}$} \\
\hline Hypothesis & & Pat & & $\begin{array}{l}\text { tandardized } \\
\text { Regression } \\
\text { coefficient }\end{array}$ & S.E. & C.R. & $p$ & Decision \\
\hline 1 & $\begin{array}{l}\text { Alienation } \\
\text { in PE }\end{array}$ & $\rightarrow$ & $\begin{array}{c}\text { School } \\
\text { happiness }\end{array}$ & -0.492 & 0.140 & -5.034 & $<0.001^{* * *}$ & Adopted \\
\hline 2 & $\begin{array}{l}\text { Alienation } \\
\text { in PE }\end{array}$ & & $\begin{array}{l}\text { Future healthy } \\
\text { life expectancy }\end{array}$ & -0.134 & 0.085 & -2.212 & $0.027^{*}$ & Adopted \\
\hline 3 & $\begin{array}{l}\text { School } \\
\text { happiness }\end{array}$ & & $\begin{array}{l}\text { Future healthy } \\
\text { life expectancy }\end{array}$ & 0.678 & 0.071 & 9.430 & $<0.001^{* * *}$ & Adopted \\
\hline
\end{tabular}

${ }^{* * *} p<0.001,{ }^{*} p<0.05$

\section{Discussion}

This study aimed to investigate the structural relationships among alienation in PE, school happiness, and future healthy life expectancy among Korean adolescents during the COVID-19 pandemic and examines the changes in the parameters and their structural relationship compared to the pre-COVID-19 period to explore measures to enhance social 
health, an essential aspect of health in adolescence. We discuss our results about the findings below.

First, there were partial changes in alienation in PE, school happiness, and future healthy life expectancy among Korean adolescents since the outbreak of the COVID-19 pandemic. More specifically, the alienation of PE facilities and uniform domains were lower during the pandemic than before. However, there were no changes in alienation in athletic competence, alienation in curriculum, and alienation in peer relationships between the two periods. These results are similar to previous findings of alienation in PE classes wherein it differs according to the educational and class environmental factors, such as PE facility and PE uniforms [30]. In particular, one reason the degree of alienation regarding PE facilities and PE uniforms changed during the COVID-19 pandemic can be attributed to the possible bad weather, field condition, and conflict regarding the use of PE uniforms during in-person PE classes. However, with the implementation of hybrid PE classes (online and in-person) during the pandemic, students were less likely to wear a uniform, and the PE classes were less affected by the weather. Hence, measures to promote students' school happiness should be devised considering that during the COVID-19 pandemic, adolescents spend most of their days in online and offline school work. This is one reason why schools continue with PE classes, even during the pandemic, by implementing hybrid designs. As previously described, various experiences acquired during PE classes affect students' school happiness. Hence, schools should strive to adopt an ideal hybrid design, wherein online classes utilize humanistic and artistic approaches to PE and involving students in physical activities, while offline classes ensure they engage in the required physical activities that feature various contents and strategies while practicing social distancing and wearing a face mask.

Second, the relationship with teachers and class environmental satisfaction domains of school happiness was higher during the pandemic than before. However, there were no changes in peer relationships, self-efficacy, and pleasure in learning activities between the two periods. These results are consistent with previous findings that interpersonal relationships with friends and teachers, academic achievement, and experiences of success in various subjects provoke happiness in students [45]. Conversely, it is similar to a previous report that students develop a negative perception of the PE class if they remain distant or feel severed from the class atmosphere and the PE teacher [49]. Further, a previous finding that students and teachers have different perceptions due to their power imbalance $[50,51]$ supports our results. Specifically, PE teachers preferred and interacted more with highly athletic students or other specific groups of students in the in-person PE classes before the pandemic [51]. However, such phenomena were alleviated in the hybrid PE classes with online and in-person sessions. The physical distance between teachers and students in online classes seems to have helped students build an equal relationship and interact with their PE teachers. Likewise, the physical distance between teachers and students in in-person classes in adherence to social distancing practices may have contributed to students' perceived fairness in the instruction. Moreover, the conflict between teachers and students over wearing a PE uniform was partially curtailed in hybrid classes. Third, the economic life expectancy domain of future healthy life expectancy was higher during the COVID-19 pandemic than before, but there were no changes in the interpersonal expectancy, healthy life expectancy, and self-realization expectancy domains. These results highlight that adolescence is a transitional period wherein individuals make critical decisions for their future. For this reason, adolescents have been reported to think positively about their future and set specific goals to carry on an independent life, even in adverse and vulnerable environments [52]. In addition, adolescents are primarily focused on their academic performance to gain college admission than engaging in self-reflection and exploring career options. They are more focused on their future economic lives since the pandemic outbreak because they see many self-employed people experiencing financial hardship and other employed workers take unpaid leave or lose their jobs amid the 
tolls of the pandemic. We can infer that students who feel happy at school develop positive expectancies of their future lives based on their accomplishments, as suggested by a previous study reporting a positive association between school happiness and defined goal setting for the future [53]. Thus, during the COVID-19 pandemic, schools need to implement programs that promote students' happiness. Schools have strived to engage students in learning through diverse hands-on experiences than simply imparting knowledge. Although such hands-on programs have been placed on hold due to the COVID-19 pandemic, creative online and in-person learning programs should be developed adhering to infection prevention guidelines because relishing school enhances learning efficiency and increases students' expectancy for the future.

Finally, before the COVID-19 pandemic, school happiness had a complete mediating effect between alienation in PE and future healthy life expectancy, wherein the former influenced latter solely through school happiness. In contrast, during the pandemic, alienation in PE, both directly and indirectly, through the mediation of school happiness, influenced future healthy life expectancies. These results suggest that PE classes have had a more direct and significant impact on adolescents' future lives since the outbreak of COVID-19 than before. In other words, while students who felt alienated in PE before the pandemic indeed felt less happy at school, they could develop positive expectancy for their future through the diverse curriculum and creative hands-on programs. However, since the pandemic outbreak, alienation in PE has influenced school happiness and their future lives. This is probably not exclusive to alienation in PE. With restrictions placed on their day-to-day lives during the pandemic, students link the microscopic phenomenon of alienation in PE to the macroscopic aspect of their future lives. Based on these results, schools should contemplate measures to reduce alienation in PE during the COVID-19 pandemic and continuously implement such strategies even after the pandemic ends to promote future healthy life expectancy in students. Ultimately, schools should also try to understand students' circumstances through emotional bonding by identifying the causes of alienation in PE during the COVID-19 pandemic. One good strategy is to assign individualized tasks or simple roles to such students during online and in-person classes to highlight their importance. The teacher needs to serve as psychological support for students, even during the COVID-19 pandemic, regardless of the class.

Taken together, adolescents with low alienation in PE displayed high school happiness and future healthy life expectancy during the pandemic. This shows that social health has a positive impact on adolescents, even during the pandemic. Although many studies argued that adolescents' physical and mental health is at risk [11-22], we observed that online and in-person hybrid PE classes promote adolescents' social healthy by lowering alienation in PE and boosting school happiness and future healthy life expectancy. To ensure adolescents' social health during the COVID-19 pandemic, Kim's (2005) [30] strategies to resolve the issue of alienation in PE should be utilized. This includes classes that: (1) allow students to enjoy various sports and improve their athletic competence; (2) allow students to learn about sports and experience the true pleasure of exercise; and (3) involve all students through sports and provides encouragement. Additionally, body consciousness and passion for sports proposed by Hwang \& Lee (2014) [42] should be considered in PE programs that target the resolution of alienation.

\section{Conclusions}

The key findings of this study are summarized as follows: First, there were partial changes in alienation in PE, school happiness, and future healthy life expectancy among Korean adolescents since the outbreak of COVID-19 than before. Specifically, the alienation in PE facilities and PE uniforms domains were lower during the COVID-19 pandemic than before, but there were no changes in alienation in athletic competence, alienation in curriculum, and alienation in peer relationships. Second, the relationship with teachers and satisfaction with class environment domains of school happiness were higher during 
the COVID-19 pandemic than before. However, there were no changes in peer relationships, self-efficacy, and pleasure in learning activities between the two periods. Third, the economic life expectancy domain of future healthy life expectancy was higher during the COVID-19 pandemic than before, but there were no changes in interpersonal relationships, healthy life, and self-realization expectancies. Finally, before the COVID-19 pandemic, there was a complete mediation wherein alienation in PE influenced future healthy life expectancy through the mediation of school happiness. However, during the pandemic, there was a partial mediation wherein alienation in PE directly and indirectly affected future healthy life expectancy through the mediation of school happiness. This suggests that adolescents were more dependent on school before COVID-19 than during the pandemic.

In conclusion, adolescence is when individuals grow into adults with desirable values by consistently interacting with various social factors and laying a foundation to design happy future lives. Hence, ensuring adolescents' social, physical, and mental health through PE to help them gain comprehensive experiences and engage in positive and proactive thinking is crucial. Even during the COVID-19 pandemic, it is important to resolve the issues of alienation in PE such that adolescents can feel various forms of satisfaction at school and thus develop positive expectancy for their future lives, as this would ultimately promote their social health. In the light of these findings, the Office of Education and relevant organizations must develop and implement various educational programs to prevent and overcome alienation in PE. We believe that our study will serve as a valuable theoretical foundation for such efforts.

Based on these findings and the limitations of this study, we present a few suggestions for subsequent studies. First, this study was conducted with the adolescent population in the Republic of Korea during the COVID-19 pandemic. Hence, the findings cannot be generalized to other countries; subsequent studies should examine students from other countries. Second, adolescents' future healthy life expectancy occurs through various factors; therefore, subsequent studies should examine an array of potential predictors of future healthy life expectancy based on our results. Third, although we used scales previously validated, future healthy life expectancy is a relatively new concept; hence, studies should validate the scale using more diverse methodologies and assess its feasibility in various research. Fourth, we established the relationships among the study parameters based on the literature. Thus, subsequent studies should establish the relationships among the parameters based on more diverse studies and theories.

Author Contributions: Study design: S.-M.L. Study conduct: S.-M.L., J.-I.Y. and H.-S.Y. Data collection: S.-M.L. and J.-I.Y. Data analysis: S.-M.L., J.-I.Y. and H.-S.Y. Data interpretation: S.-M.L. and J.I.Y. Drafting the manuscript: S.-M.L., J.-I.Y. and H.-S.Y. Revising the manuscript content: S.-M.L., J.I.Y. and H.-S.Y. All authors have read and agreed to the published version of the manuscript.

Funding: This research received no external funding.

Institutional Review Board Statement: The study was conducted according to the guidelines of the Declaration of Helsinki, and conducted with the approval of the Korea National Institute for Bioethics Policy IRB (P01-202006-22-001).

Informed Consent Statement: Informed consent was obtained from all subjects involved in the study.

Data Availability Statement: The data presented in this study are available on request to the authors. Some variables are restricted to preserve the anonymity of study participants.

Conflicts of Interest: The authors declare no conflicts of interest.

\section{References}

1. Korean Ministry of Health and Welfare. Response strategies in response to the COVID-19 phenomenon. Seoul; Korea, 2020.

2. Cullen, W., Gulati, G., \& Kelly, B. D. Mental health in the Covid-19 pandemic. QJM: An International Journal of Medicine 2020, 113(5), 311-312. doi: 10.1093/qjmed/hcaa110 
3. Mazza, C., Ricci, E., Biondi, S., Colasanti, M., Ferracuti, S., Napoli, C., \& Roma, P. A nationwide survey of psychological distress among Italian people during the COVID-19 pandemic: immediate psychological responses and associated factors. Int. J. Environ. Res. Public Health 2020, 17(9), 3165. doi: 10.3390/ijerph17093165

4. Zhang, J., Lu, H., Zeng, H., Zhang, S., Du, Q., Jiang, T., \& Du, B. The differential psychological distress of populations affected by the COVID-19 pandemic. Brain, behavior, and immunity 2020, 87, 49. doi: 10.1016/j.bbi.2020.04.031

5. Wilke, J., Mohr, L., Tenforde, A. S., Edouard, P., Fossati, C., González-Gross, M., Ramirez, C. S., Laiño, F., Tan, B. , Pillay, J. D., Pigozzi, F., Jimenez-Pavon, D, Novak, B, Jaunig, J., Zhang, M, Poppel, M., Heidt, C, Willwacher, S., Yuki, G., Lieberman, D. E., Vogt, L., Verhagen, E., Hespanhol, L., \& Hollander, K. (2021). A pandemic within the pandemic? Physical activity levels substantially decreased in countries affected by COVID-19. Int. J. Environ. Res. Public Health 2021, 18(5), 2235. doi: 10.3390/ijerph18052235

6. Woods, J. A., Hutchinson, N. T., Powers, S. K., Roberts, W. O., Gomez-Cabrera, M. C., Radak, Z., Berkes, I., Boros, A., Boldogh, I., Leeuwenburgh, L., Coelho-Júnior, H. J., Marzetti, E., Cheng. Y., Liu, J., Durstinem, J. L., Sun, J., \& Ji, L. L. The COVID-19 pandemic and physical activity. Sports Medicine and Health Science 2020, 2(2), 55-64. doi: 10.1016/j.smhs.2020.05.006

7. Dwyer, M. J., Pasini, M., De Dominicis, S., \& Righi, E. Physical activity: Benefits and challenges during the COVID-19 pandemic. Scandinavian journal of medicine $\mathcal{E}$ science in sports 2020, 30(7), 1291. doi: 10.1111/sms.13710

8. Guessoum, S. B., Lachal, J., Radjack, R., Carretier, E., Minassian, S., Benoit, L., \& Moro, M. R. Adolescent psychiatric disorders during the COVID-19 pandemic and lockdown. Psychiatry research 2020, 113264. doi: 10.1016/j.psychres.2020.113264

9. Imran, N., Zeshan, M., \& Pervaiz, Z. Mental health considerations for children \& adolescents in COVID-19 Pandemic. Pakistan journal of medical sciences 2020, 36(COVID19-S4), S67-S72. doi: 10.12669/pjms.36.COVID19-S4.2759

10. Fegert, J. M., Vitiello, B., Plener, P. L., \& Clemens, V. Challenges and burden of the Coronavirus 2019 (COVID-19) pandemic for child and adolescent mental health: a narrative review to highlight clinical and research needs in the acute phase and the long return to normality. Child and adolescent psychiatry and mental health 2020, 14, 1-11. doi: 10.1186/s13034-020-00329-3

11. Ezpeleta, L.; Navarro, J.B.; de la Osa, N.; Trepat, E.; Penelo, E. Life conditions during COVID-19 lockdown and mental health in Spanish adolescents. Int. J. Environ. Res. Public Health 2020, 17, 7327, doi:10.3390/ijerph17197327.

12. Jones, E.A.; Mitra, A.K.; Bhuiyan, A.R. Impact of COVID-19 on mental health in adolescents: A systematic review. Int. J. Environ. Res. Public Health 2021, 18, 2470, doi:10.3390/ijerph18052470.

13. Meherali, S.; Punjani, N.; Louie-Poon, S.; Abdul Rahim, K.; Das, J.K.; Salam, R.A.; Lassi, Z.S. Mental health of children and adolescents amidst CoViD-19 and past pandemics: A rapid systematic review. Int. J. Environ. Res. Public Health 2021, 18, 3432, doi:10.3390/ijerph18073432.

14. Nearchou, F.; Flinn, C.; Niland, R.; Subramaniam, S.S.; Hennessy, E. Exploring the impact of COVID-19 on mental health outcomes in children and adolescents: A systematic review. Int. J. Environ. Res. Public Health 2020, 17, 8479, doi:10.3390/ijerph17228479.

15. O'Sullivan, K.; Clark, S.; McGrane, A.; Rock, N.; Burke, L.; Boyle, N.; Joksimovic, N.; Marshall, K. A qualitative study of child and adolescent mental health during the COVID-19 pandemic in Ireland. Int. J. Environ. Res. Public Health 2021, 18, 1062, doi:10.3390/ijerph18031062.

16. Pietrabissa, G., Volpi, C., Bottacchi, M., Bertuzzi, V., Usubini, A. G., Löffler-Stastka, H., Prevendar, T., Rapelli, G., Cattivelli, R., Castelnuovo, G., Molinari, E., \& Sartorio, A. The impact of social isolation during the covid-19 pandemic on physical and mental health: The lived experience of adolescents with obesity and their caregivers. Int. J. Environ. Res. Public Health 2021, $18(6), 3026$. doi: 10.3390/ijerph18063026

17. Lee, S.M.; So, W.Y.; Youn, H.S. Importance-performance analysis of health perception among Korean adolescents during the COVID-19 pandemic. Int. J. Environ. Res. Public Health 2021, 18, 1280, doi:10.3390/ijerph18031280.

18. Yoo, J. I., Han, J. K., Youn, H. S., \& Jung, J. H. Comparison of Health Awareness in South Korean Middle School Students According to Type of Online Physical Education Classes During the COVID-19 Pandemic. Int. J. Environ. Res. Public Health 2021, 18(15), 7937; https://doi.org/10.3390/ijerph18157937.

19. Bronikowska, M.; Krzysztoszek, J.; Łopatka, M.; Ludwiczak, M.; Pluta, B. Comparison of physical activity levels in youths before and during a pandemic lockdown. Int. J. Environ. Res. Public Health 2021, 18, 5139, doi:10.3390/ijerph18105139.

20. Nobari, H.; Fashi, M.; Eskandari, A.; Villafaina, S.; Murillo-Garcia, Á.; Pérez-Gómez, J. Effect of COVID-19 on health-related quality of life in adolescents and children: A systematic review. Int. J. Environ. Res. Public Health 2021, 18, 4563, doi:10.3390/ijerph18094563.

21. Lee, S.M.; So, W.Y.; Youn, H.S. Importance-performance analysis of health perception among Korean adolescents during the COVID-19 pandemic. Int. J. Environ. Res. Public Health 2021, 18, 1280, doi:10.3390/ijerph18031280.

22. Mastorci, F.; Bastiani, L.; Trivellini, G.; Doveri, C.; Casu, A.; Pozzi, M.; Marinaro, I.; Vassalle, C.; Pingitore, A. Well-being perception during COVID-19 pandemic in healthy adolescents: From the Avatar Study. Int. J. Environ. Res. Public Health 2021, 18, 6388, doi:10.3390/ijerph18126388.

23. Gottheil, N. F., \& Dubow, E. F. Tripartite beliefs models of bully and victim behavior. Journal of Emotional Abuse 2001, 2(2-3), 2547. doi: 10.1300/J135v02n02_03

24. Orpinas, P., \& Horne, A. M. Bullying prevention: Creating a positive school climate and developing social competence. American Psychological Association 2006.

25. Physical Activity Guidelines Advisory Committee. Physical activity guidelines advisory committee report 2008. Washington, DC: US Department of Health and Human Services 2008, A1-H14. 
26. Hellison, D. R., Cutforth, N., Kallusky, J., Martinek, T., Parker, M., \& Stiehl, J. Youth development and physical activity: Linking universities and communities, Human Kinetics, 2000.

27. Sallis, J. F., \& McKenzie, T. L. Physical education's role in public health. Research quarterly for exercise and sport 1991, 62(2), 124137. doi: 10.1080/02701367.1991.10608701

28. Kim, J. H. \& Jung, C. W. Relation Between Mental Health and Academic Achievement of Korean Teenagers in Accordance with Physical Education and Physical Activity. Korean Journal of Sports Science 2012, 21(6), 553-570.

29. Carlson, T. B. (1995). We hate gym: Student alienation from physical education. Journal of Teaching in Physical Education 1995, 14(4), 467-477. https://doi.org/10.1123/jtpe.14.4.467

30. Kim, Y. H. Development and validation of the alienation in physical education scale. Korean Journal of Sport Pedagogy 2005, 12(3), 121-142.

31. Fox, K. R., \& Biddle, S. J. The use of fitness tests: Educational and psychological considerations. Journal of Physical Education, Recreation \& Dance 1988, 59(2), 47-53. doi: 10.1080/07303084.1988.10609691

32. Rice, P. L. Attitudes of high school students toward physical education activities, teachers, and personal health. Physical Educator 1988, 45, 94-99.

33. Allison, P. C., Pissanos, B. W., \& Sakola, S. P. Physical education revisited -the institutional biographies of preservice classroom teachers. Journal of Physical Education, Recreation \& Dance 1990, 61(5), 76-79. doi: 10.1080/07303084.1990.10604524.

34. Figley, G. E. Determinants of attitudes toward physical education. Journal of Teaching in Physical Education 1985, 4(4), 229-240. doi: $10.1123 /$ jtpe.4.4.229

35. Luke, M. D., \& Sinclair, G. D. Gender differences in adolescents' attitudes toward school physical education. Journal of Teaching in physical Education 1991, 11(1), 31-46. doi: 10.1123/jtpe.11.1.31

36. Robinson, D. W. An attributional analysis of student demoralization in physical education settings. Quest 1990, 42(1), 27-39. doi:10.1080/00336297.1990.10483977

37. Macintosh, D., \& Albinson, J. Physical education in Ontario secondary schools. The Canadian Association for Health, Physical Education, Recreation and Dance 1982, 48, 14-17. doi: 10.1080/00336297.1990.10483977

38. Song, K. O. Exploring school characteristics affecting students' happiness. Journal of Korean Education 2011, 38(4), $39-64$.

39. Annas, J. Happiness as achievement. Daedalus 2004, 133(2), 44-51. doi:10.1162/001152604323049389

40. Kim, S. J.; Lee, C. H. \& Ahn, S. W. Structural relationships among physical class satisfaction, body image, and future life expectation of elementary school students. Journal of Learner-Centered Curriculum and Instruction 2014, 14(3), 193-211.

41. Seginer, R., Vermulst, A., \& Shoyer, S. The indirect link between perceived parenting and adolescent future orientation: A multiple-step model. International Journal of Behavioral Development 2004, 28(4), 365-378. doi:10.1080/01650250444000081

42. Yang, B. H. Understanding Multivariate Data Analysis; Communication Books, Seoul, Korea, 2006.

43. Kim, A. Y., Cha, J. E. The basics of statistical analysis logic; Bakhak-sa press, Seoul, Korea, 2006.

44. Hwang, S. H. \& Lee, C. S. The subjected effects of body consciousness and passion for sports on alienation in physical education. Korean Journal of Physical Education 2014, 53(1), 77-92.

45. Seo, Y. H., Lee, D. H., \& Song, J. H. Physical education class in elementary school alienation and stress relationships. The Korean Society for the Study of Physical Education 2011, 16(1), 169-180.

46. Lee, S. J. Relationship among self-determined motives, self-efficacy and school happiness of middle school students participating in school sports clubs. Korean Journal of Sport 2017, 15(2), 37-49.

47. Noh, Y. J. A study on the quality of life of adults in the middle age of Seoul; Unpublished doctoral dissertation, Yonsei University, Seoul, Korea, 1988.

48. Kim, J. B. \& Kim, T. E. The development and validation of the Korean school happiness scale. Korean Journal of Educational Psychology 2008, 22(1), 259-279.

49. Kim, D. J. Causes of alienation in physical education from the perspectives of middle school students. Korean Journal of Sport Pedagogy 2010, 17(3), 1-21.

50. Martel, D., Gagnon, J., \& Tousignant, M. Physical education teachers' and students' views of injustices in the gymnasium. AVANTE-ONTARIO- 2002, 8(1), 55-68.

51. Napper-Owen, G. E. Justice for All: Equity in the Elementary Gymnasium. Strategies 1994, 8(3), $23-26$.

52. Yoo, J. S. A study on effects of future orientation on psychosocial variables among korean adolescents. Unpublished master's thesis, KyungHee University, Seoul, Korea, 2007.

53. Kwak, S. R. The effect of future goal consciousness in adolescence on personal competence and happiness in early adulthood. Journal of Korean Education 2018. 45(4), 5-34. 